\title{
书 讯
}

\section{新生物学丛书一领跑中国生命科学}

IIID科学出片社 www.sciencep.com

当前, 一场新的生物学革命正在展开. 为此, 美国国家科学院研究 理事会于 2009 年发布了一份战略研究报告, 提出一个“新生物学”(New Biology)时代即将来临. 这个“新生物学”, 一方面是生物学内部各种分支 学科的重组与融合, 另一方面是化学、物理、信息科学、材料科学等众多 非生命学科与生物学的紧密交叉与整合.

在这样一个全球生命科学发展变革的时代, 我国的生命科学研究也 正在高速发展，并进入了一个充满机遇和挑战的黄金期. 在这个时期, 将 会产生许多具有影响力、推动力的科研成果, 《新生物学丛书》通过系统 性集成和出版相关主题的国内外优秀图书, 预测生命科学前沿、交叉新方 向, 为科学管理者和科研人员展示科学的最新动向; 展示生命科学前沿、 交叉学术成果, 为专业工作者提供新思想和新方法; 发表高级科普著作, 为不同领域的研究人员和科学爱好者普及生命科学的前沿知识.

《新生物学丛书》是开放式的，为了保证丛书的质量，所有单本书都 要经过编委会审查准入. 编委会主任是美籍华人蒲慕明, 这位著名的神 经生物学家是美国国家科学院院士、中国科学院院士，学术成就高, 堪称 中国生命科学的一面旗帜. 在他的带领下, 由 32 名生命科学各领域的学 术领军人物组成了阵容强大的编委会.

此次从书出版了 3 本重要著作: 《细胞的生物物理学》(译), 这是一本 系统论述如何应用物理学基本原理来理解生命现象及其规律的优秀著作. 内容丰富, 物理学模型与生物学实 例有机结合, 是从“卡通图解生物学”向“现代定量生物学”发展历程中不可多得的教材和研究参考书(中国科学 院理论物理研究所欧阳钟灿院士), 是一本物理学家进入生命科学领域的入门教材, 更是生物学家学习数理工 具的参考书(中国科学院上海药物所蒋华良研究员); 《间充质干细胞基础与临床》, 关注的是最具临床应用前 景的干细胞一一间充质干细胞, 《基因组学: 核心技术方法》是在基因组学影响力日益扩大, 新技术不断产生, 海量数据迅速积累的背景下, 为生命科学各个领域提供方法, 书中包含了基因组学领域的最新信息, 非常适 合于从事基因组学及其在生命科学领域的各个衍生学科研究的人员阅读.

丛书 2012 年内即将再出版 6 种: 《21 世纪的新生物学》、《比较蛋白质组学和生物信息学》、《植物转基因技 术》、《合成生物学》、《延续生命一人类健康与生物多样性》、《纳米孔: 传感和生物相互作用的基本原则》、《纳 米生物传感》.

《新生物学丛书》是 21 世纪中国生命科学的传播平台, 也是生命科学革命上演的舞台, 丛书将记录生命科 学的进步，帮助科研人员得到新的知识信息，给予他们思考与启迪，从而向更高的科研层次冲击. 